\title{
ABSTRAK \\ POTENSI AKAR WANGI (Vetivera zizanioides) DALAM MEREHABILITASI TANAH TERCEMAR LOGAM BERAT TIMBAL (Pb) DI PERKEBUNAN SAYUR DESA WAIHERU AMBON
}

\author{
Deli Wakano dan Efraim Samson \\ Jurusan Biologi FMIPA Unpatti
}

\begin{abstract}
Adapun tujuan dari penelitian ini adalah untuk mengetahui potensi akar wangi (Vetivera zizanioides) dalam merehabilitasi tanah tercemar logam berat timbal $(\mathrm{Pb}) \mathrm{di}$ perkebunan sayur Desa Waiheru. Target luaran yang ingin dicapai adalah meminimalkan penggunaan pestisida yang berdampak negatif bagi lingkungan, mengurangi kandungan logam berat pada timbal pada perkebunan sayur, agar sayur yang kita komsumsi aman dari zat-zat yang berbahaya bagi tumbuh. Metode yang digunakan adalah metode eksperimen laboratorik dengan menggunakan 4 (empat) tahapan penelitian yaitu tahapan pertama: Pengambilan tanah dilapangan, Tahapan kedua: Analisis kandungan logam berat timbal $(\mathrm{Pb})$ pada tanah, Tahapan ketiga: Persiapan tanah dirumah kaca, tahapan ke empat: Pengujian kandungan $\mathrm{Pb}$ pada tanaman akar wangi setelah penanaman. Hasil yang ditemukan adalah 1. Terdapat Logam berat Timbal di perkebunan Waiheru Kota Ambon, 2. Kandungan logam berat timbal dalam tanah perkebunan Waiheru masih berada di bawah ambang batas aman yaitu 0,1114 - 0,2882 ppm. 3. Akar Wangi Mampu meremediasi tanah tercemar timbal $(\mathrm{Pb})$ berkisar antara $71,08 \%-73,71 \%$.
\end{abstract}

\section{Kata kunci : Akar Wangi, Logam Berat (Pb)}

\section{PENDAHULUAN}

Pemanfaatan tanah sebagai sumberdaya alam dalam berbagai sektor akhir-akhir ini semakin luas dengan semakin meningkatnya kebutuhan manusia. Pemanfaatan tanah yang melebihi daya dukung dan daya tampungnya akan menyebabkan terjadinya kerusakan mutu sumberdaya tanah. Dalam PP No.150/2000 tentang pengendalian kerusakan tanah untuk produksi bimassa, kerusakan tanah didefinisikan sebagai " berubahnya sifat dasar tanah, yaitu sifat fisik, kimia dan biologi tanah yang melampui kriteria baku kerusakan tanah. Menurut Barrow (1991) dan Steiner (1996) penyebab kerusakan tanah antaara lain bencana alam (gempa, longsor dan banjir) erosi, pemadatan, penurunana kadar bahan organik dan unsur hara serta pencemaran bahan agrokimia (pestisida, herbisida, fungisida, pupuk dan bahan kimia lain seperti logam berat). Pencemaran logam berat sebagai salah satu penyebab kerusakan mutu tanah dapat berasal dari asap kendaraan bermotor, bahan bakar minyak, pupuk pertanian dan pestisida, pupuk organik, buangan limbah rumah tangga maupun 
industri dan limbah pertambangan. Selain itu, sumber logam berat dapat berasal dari bahan induk pembentuk tanah (Alloway, 1995). Kekhawatiran tentang pencemaran logam berat dalam tanah berkaitan dengan (1) akumulasi logam berat dalam tanah yang dalam jangka panjang akan berpengaruh terhadap kualitas dan kuantitas hasil tanaman, (2) serapan logam berat dalam tanaman membahayakan kesehatan manusia dan ternak, serta (3) menurunkan kualitas tanah dan membahayakan keanekaragaman hayati dalam tanah. Untuk itu maka perlu adanya rehabilitas tanah di perkebunan Waiheru Ambon, sehingga hasil tanaman yang kita komsumsi aman dan tanahpun menjadi tidak tercemar lagi.

Salah satu tumbuhan yang digunakan sebagai usaha rehabilitas tanah adalah akar wangi. Akar wangi (Vetiveire zizanioides $L$ ) tergolong tumbuhan serba guna yang secara ekonomis memberikan berbagai keuntungan, antara lain akarnya untuk menghasilkan minyak atsiri sebagai bahan baku obat dan kosmetik, batang dan daunnya untuk berbagai kerajinan tangan (tas dan topi), untuk bahan baku kertas, dan beberapa jenis/varietas diantaranya dapat menjadi sumber pakan ternak (Sukmana, 1996). Selain itu tumbuhan ini mampu tumbuh baik diberbagai tipe dan kondisi tanah, keadaan iklim yang ekstrim, maupun pada tanah tercemar berbagai jenis logam berat. Pemanfaatan tanaman akar wangi untuk pengendalian pencemarana lingkungan, misalnya untuk mengurangi kadar logam berat dan pestisidasi belum banyak dilakukan. Berdasarkan hal tersebut maka perlu ada penelitian tentang potensi akar wangi (Vetiveira zizanioides L) dalam merehabilitasi tanah yang tercemar logam berat dan pestisidasi.

\section{METODE PENELITIAN}

\section{Tipe Penelitian}

Adapun jenis penelitian ini adalah eksperimen.

\section{Tempat dan waktu Penelitian}

Penelitian ini dilakukan di Laboratorium Ekologi dan di Rumah Kaca FMIPA Unpatti. Waktu penelitian ini direncanakan selama 3 (tiga) bulan yaitu mulai Mei sampai juli 2015

\section{Sumber Sampel}

1. Sampel tanah diambil di perkebunan sayur Desa Waiheru 
2. Sampel Tanaman akar wangi diambil di Wilayah kampus IAIN dan sekitarnya.

\section{Alat dan Bahan Penelitian}

Alat dan bahan yang digunakan dalam penelitian ini adalah sekop, trofol, polybag, sarung tangan, sampel tanah, kertas lebel, oven, AAS, ayakan tanah, HNO3 pekat, HCL pekat, , kertas whatman 42, aquades.

\section{Prosedur Penelitian}

\section{a. Tahap Pertama : Pengambilan Tanah di Lapangan}

Pengambilan tanah dilakukan pada perkebunan Desa Waiheru Ambon. Sebelum dilakukan pengambilan tanah, terlebih dahulu dilakukan pengamatan lapangan untuk melihat keragaman lahan yang meliputi kondisi fisik lingkungan. Selanjutnya ditentukan 3 titik observasi pengambilan contoh tanah sebegai media tanah akar wangi pada percobaan rumah kaca. Contoh tanah diambil terlebih dahulu diayak dengan ayakan pasir berdiameter $1 \mathrm{~cm}$ untuk memperoleh butiran - butiran tanah yang kecil dan untuk membersihkan tanah dari batu kerikil, serasah, bekas akar tanaman atau bahan kasar lainnya. Kemudian dibawah ke laboratorium Ekologi FMIPA Unpatti untuk dianalisis kandungan logam beratnya.

\section{b.Tahap Kedua : Analisis Kandungan logam berat pada Tanah}

Analisis kadar logam berat tanah menggunakan contoh tanah permukaan yaitu pada kedalaman 0-20 cm dari permukaan tanah. Pengambilan contoh tanah tersebut bertujuan untuk mengetahui total kandungan logam berat yang berasal dari tanah permukaan. Dalam analisis kandungan logam berat contoh tanah permukaan 0-20 cm sebelum dilakukan pengabuan, terlebih dahulu contoh tanah tersebut dipanaskan dengan menggunakan oven dengan suhu $60{ }^{\circ} \mathrm{C}$ hingga mencapai kering udara (selama 24 jam), kemudian dilanjutkan dengan pengeringan dengan oven pada suhu $105{ }^{\circ} \mathrm{C}$ hingga kering sampai beratnya tidak berubah. selanjutnya contoh tanah yang kering dilakukan pengabuan basah dengan menggunakan prosedur Balai Penelitian Tanah (2005). Hasil akhir dari pengabuan basah tersebut berupa cairan $10 \mathrm{ml}$ yang telah dikocok, kemudian dibaca AAS dan hasil absorbansinya setelah dikonversi dalam satuan ppm dikalikan dengan 10. Setelah diketahui 
kandungan logam beratnya kemudian tanah tersebut dijadikan untuk media tanah akar wangi (Vetiveria zizanoides L).

\section{c. Tahap Ketiga: Persiapan Tanah di Rumah Kaca}

Tanah yang sudah diketahui kandungan logam beratnya selanjutya diambil $10 \mathrm{~kg}$ untuk masing - masing pot percobaan, kemudian dilakukan penanaman akar wangi, setiap 1 minggu dilakukan sekali penyiraman agar tanaman akar wangi tidak kekeringan. Penyiraman ini dilakukan setelah akar wangi ditanam sampai selang waktu 2 bulan. Setelah itu dianalisis kandungan logam berat pada tanah tersebut.

\section{d. Tahap Keempat : Pengujian kandungan logam berat setelah penanaman Akar wangi}

Untuk mengetahui apakah akar wangi mampu merehabilitas tanah perkebunan Desa Waeheru maka dilakukan analisis kadar logam berat pada tanah yang sudah ditanam akar wangi tersebut. Dan prosedurnya sam dengan analisis kandungan logam berat sebelum dilakukan penanaman.

\section{Teknik Analisis Data}

Potensi tanaman sebagai rehabilitasi dilakukan dengan menghitung akumulasi dalam tanah, sebagai berikut:

$$
\frac{X 0-X 1}{X 0} \quad x 100 \%
$$

Selanjutnya analisis data perhitungan efisiensi penurunan $\mathrm{Pb}$ dan efisiensi akumulasi oleh tanaman Akar Wangi menggunakan analisis varian (ANOVA) dan dilanjutkan dengan Uji BNT pada tingkat signifikansi $5 \%$.

\section{HASIL PENELITIAN}

\section{Analisis Pendahuluan}

Analisis pendahuluan dilakukan untuk mengetahui karakeristik tanah yang digunakan pada penelitian ini. Karakteristik tanah yang dianalisa pada penelitian ini adalah $\mathrm{pH}$ dan tekstur tanah. Tanah yang akan dianalisa terdiri dari tanah awal atau tanah pasir berlempung yang belum mendapatkan perlakukan dan tanah setelah mengalami proses pemupukan. Hasil analisa tanah tersebut dapat dilihat pada Tabel 1 di bawah ini :

Tabel 1. Hasil Analisis pH dan Tekstur Tanah 


\begin{tabular}{|ccl|}
\hline Tanah & pH & \multicolumn{2}{c|}{ Tekstur Tanah } \\
\hline Tanah Awal & 3,2 & Terasa kasar, dapat dibentuk menjadi \\
Tanah setelah Pemupukan & 7,1 & $\begin{array}{l}\text { bola tetapi mudah hancur, sedikit } \\
\text { melekat dan berlumut }\end{array}$ \\
\hline
\end{tabular}

Berdasarkan tabel 1 tersebut diatas dapat dijelaskan bahwa $\mathrm{pH}$ tanah awal berbeda dengan $\mathrm{pH}$ tanah setelah pemupukan dengan tekstur tanah pasir berlempung dengan ciri-ciri terasa kasar, dapat dibentuk menjadi bola tetapi mudah hancur, sedikit melekat dan berlumut. Hasil analisis pH pada penelitian ini bersifat sangat asam, yaitu 3,2. Berdasarkan kriteria unsur hara tanah nilai $\mathrm{pH}$ tersebut termasuk tanah sangat asam $(<4,5)$. Tingkat kemasaman tanah yang tinggi dipengaruhi oleh keberadaan asam-asam organik di dalamnya. Ion $\mathrm{H}+$ dalam tanah berada dalam bentuk gugus fungsional asam-asam organik terutama dalam bentuk gugus karboksilat $\quad(-\mathrm{COOH})$ dan gugus hidroksil dari fenolat $(-\mathrm{OH})$. Gugus tersebut merupakan asam lemah yang dapat terdissosiasi menghasilkan ion $\mathrm{H}+$, dan mampu mempertahankan reaksi tanah terhadap perubahan kemasaman tanah (Riwandi, 2001 dalam Novandi, 2014). Tanah yang memiliki $\mathrm{pH}$ terlalu asam seperti tanah pada penelitian ini dapat menyebabkan kemampuan akar tanaman dalam menyerap unsur-unsur hara dalam tanah menjadi berkurang. Pada umumnya unsur hara makro mudah diserap akar tanaman pada $\mathrm{pH}$ tanah sekitar netral, karena pada $\mathrm{pH}$ tersebut kebanyakan unsur hara mudah larut dalam air. Selain itu, tabel 1 tersebut diatas dapat dijelaskan bahwa $\mathrm{pH}$ pada saat pemberian pupuk organik sebagai penambah unsur-unsur hara yang diperlukan oleh tanaman secara tidak langsung juga dapat meningkatkan nilai $\mathrm{pH}$ tanah. Nilai $\mathrm{pH}$ pupuk organik yang bersifat netral menyebabkan naiknya tingkat kebasaan tanah.

\section{Analisis Timbal Pada Tanah Perkebunan Waeheru}

Analisis data kadar timbal pada perkebunan sayur waiheru dilakukan secara deskriptif melalui data hasil pengukuran dengan menggunakan tabel dan grafik. Hasil analisis timbal pada sampel yang diperoleh dari penelitian akan dibandingkan dengan standar Baku Mutu (Peterson dan Alloway (1979) dalam Darmono (1995). Data analisis timbal tersebut dapat dilihat pada tabel 2 berikut ini:

Tabel 2 Analisis Timbal Pada Perkebunan Waiheru 


\begin{tabular}{|c|c|c|c|}
\hline Sampel & $\begin{array}{l}\text { Konsentrasi Timbal } \\
\text { Terukur (ppm) }\end{array}$ & & $\begin{array}{c}\text { Standar Baku Mutu } \\
\text { (Peterson dan Alloway } \\
\text { (1979) dalam Darmono } \\
\text { (1995) }\end{array}$ \\
\hline A1 & 0,2881 & \multirow{3}{*}{0,2882} & \multirow{9}{*}{$1-10 \mathrm{ppm}$} \\
\hline A2 & 0,2892 & & \\
\hline A3 & 0,2875 & & \\
\hline B1 & 0,1605 & \multirow{3}{*}{0.1613} & \\
\hline B2 & 0,1712 & & \\
\hline B3 & 0,1522 & & \\
\hline $\mathrm{C1}$ & 0,1106 & \multirow{3}{*}{0,1114} & \\
\hline $\mathrm{C} 2$ & 0,1115 & & \\
\hline C3 & 0,1122 & & \\
\hline
\end{tabular}

Ket: $\quad$ A1-A3 = Kebun sayur Bagian Luar

B1-B3 = Kebun sayur Bagian Tengah

C1-C3 = Kebun Sayur Bagian Dalam

Berdasarkan tabel 2 dapat dijelaskan bahwa kandungan timbal yang terdapat pada kebun bagian luar (dekat dengan jalan) lebih tinggi dibandingkan dengan kandungan timbal pada kebun bagian tengah dan dalam. Hal ini disebabkan karena semakin meningkatnya jumlah kendaraan yang melewati tempat ditanamnya sayur merupakan salah satu penyumbang logam timbal yang akan mencemari udara disekitar perkebunan tersebut. Selain itu dapat disebabkan karena kontaminasi debu dan asap kendaraan dari bahan bakar yang mengandung logam timbal. Perbandingan kandungan logam timbal pada setiap Titik dapat dilihat pada grafik 1 berikut ini: 


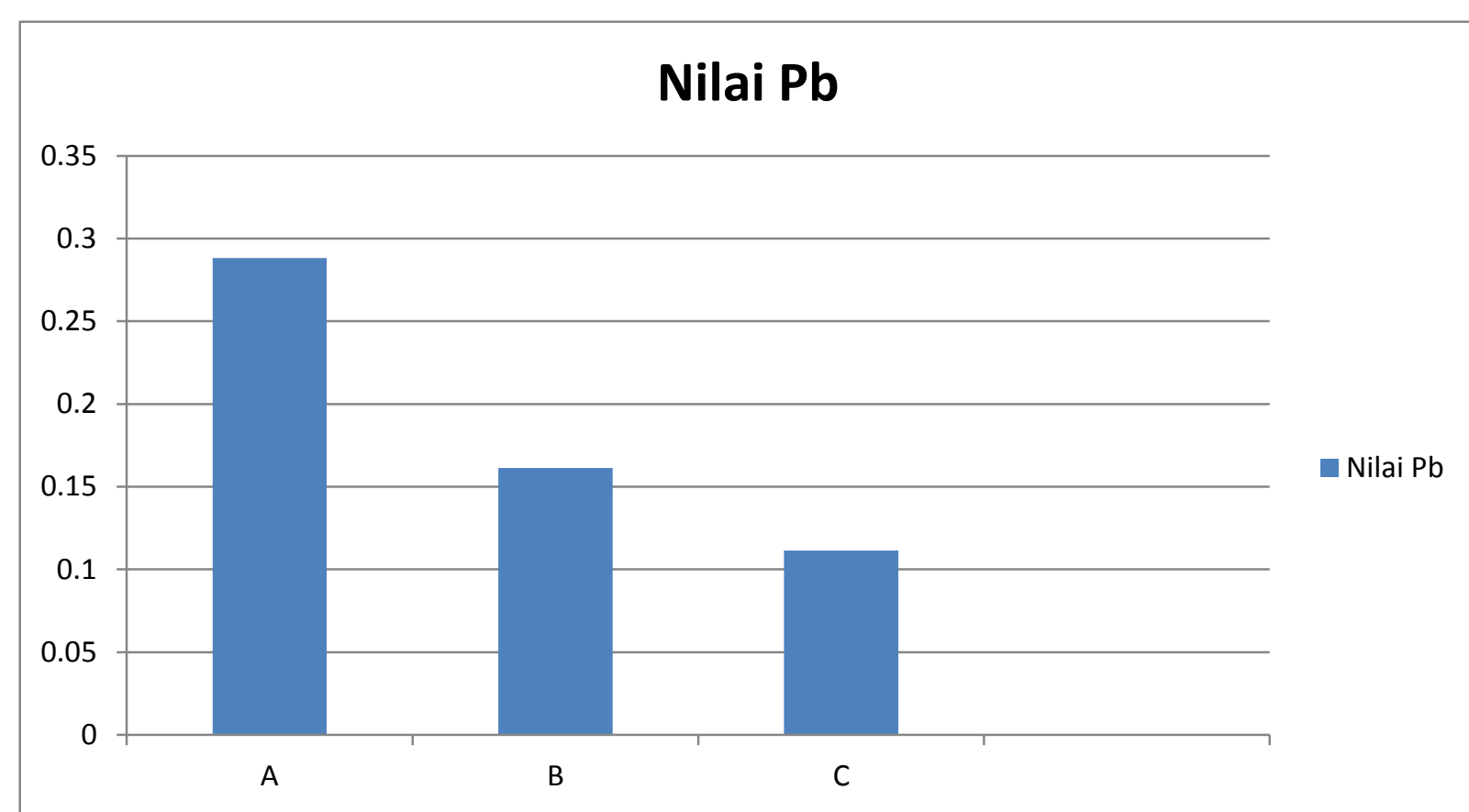

Grafik 1. Perbandingan Kandungan Logam Timbal Pada Setiap Titik Di Perkebunan Waiheru

Dari grafik 1 diatas terdapat perbedaan kandungan logam timbal pada setiap titik berdasarkan jarak pengambilan sampel dari luar sampai dalam dari perkebunan sayur. Kandungan logam timbal pada kebun bagian luar pada masing-masing sampel adalah 0,2881 ppm, 0,2892 ppm, 0,2875 ppm dengan rata rata 0,2882 ppm, pada kebun bagian tengah adalah 0,1605 ppm, 0,1712 ppm, 0,1522 ppm dengan rata-rata 0.1613 ppm dan bagian dalam adalah $0,1106 \mathrm{ppm}, 0,1115 \mathrm{ppm}, 0,1122 \mathrm{ppm}$ dengan rata-rata 0,114

Sampel Tanah pada stasiun 1 yang berjarak 1 meter dari jalan raya memiliki kandungan logam timbal lebih tinggi daripada stasiun 2 dan 3. Besarnya kandungan logam timbal yang terdapat dalam setiap titik berasal dari gas buangan kendaraan bermotor yang akan terbang ke udara sehingga dengan adanya angin dan hujan akan mengakibatkan debu tersebut jatuh ke permukaan tanah dan jalan raya sehingga dapat mencemari tanah. Selain itu juga dapat disebabkan penggunaan pestisida yang berlebihan. (Mariti, 2005).

Kandungan logam berat dalam tanah dipengaruhi oleh beberapa faktor, diantaranya jenis tanah dan kondisi tanah, selain itu logam berat masuk ke lingkungan tanah melalui penggunaan bahan kimia yang langsung mengenai tanah, penimbunan debu, hujan, pengikisan tanah dan limbah buangan (Darmono,1995). 
Kandungan logam timbal dalam tanah perkebunan Waiheru masih berada di bawah ambang batas aman yaitu 0,1114 - 0,2882 ppm. Pembuangan limbah ke tanah apabila melebihi kemampuan tanah dalam mencerna limbah akan mengakibatkan pencemaran tanah. Logam dapat menyebabkan timbulnya suatu bahaya pada makhluk hidup. Hal ini terjadi jika sejumlah logam mencemari lingkungan. Logam logam tertentu sangat berbahaya bila ditemukan dalam konsentrasi tinggi dalam lingkungan (dalam air, tanah dan udara), karena logam tersebut mempunyai sifat yang merusak jaringan tubuh makhluk hidup. Pencemaran lingkungan oleh logam-logam berbahaya $(\mathrm{Cd}, \mathrm{Pb}, \mathrm{Hg})$ dapat terjadi jika orang atau pabrik yang menggunakan logam tersebut untuk proses produksinya tidak memperhatikan keselamatan lingkungan (Darmono, 1995).

\section{Persiapan Tanah di Rumah Kaca}

Tanah yang sudah diketahui kandungan logam beratnya selanjutnya diambil $10 \mathrm{~kg}$ untuk masing-masing pot percobaan, kemudian dilakukan penanaman akar wangi, setiap 1 minggu dilakukan sekali penyiraman agar tanaman akar wangi tidak kekerinagn. Penyiraman ini dilakukan setelah akar wangi ditanam sampai selang waktu 2 bulan. Setalah itu dianalisis logam berat pada tanah tersebut. Proses penanaman akar wangi tersebut dapat dilihat pada gambar 1 berikut ini:

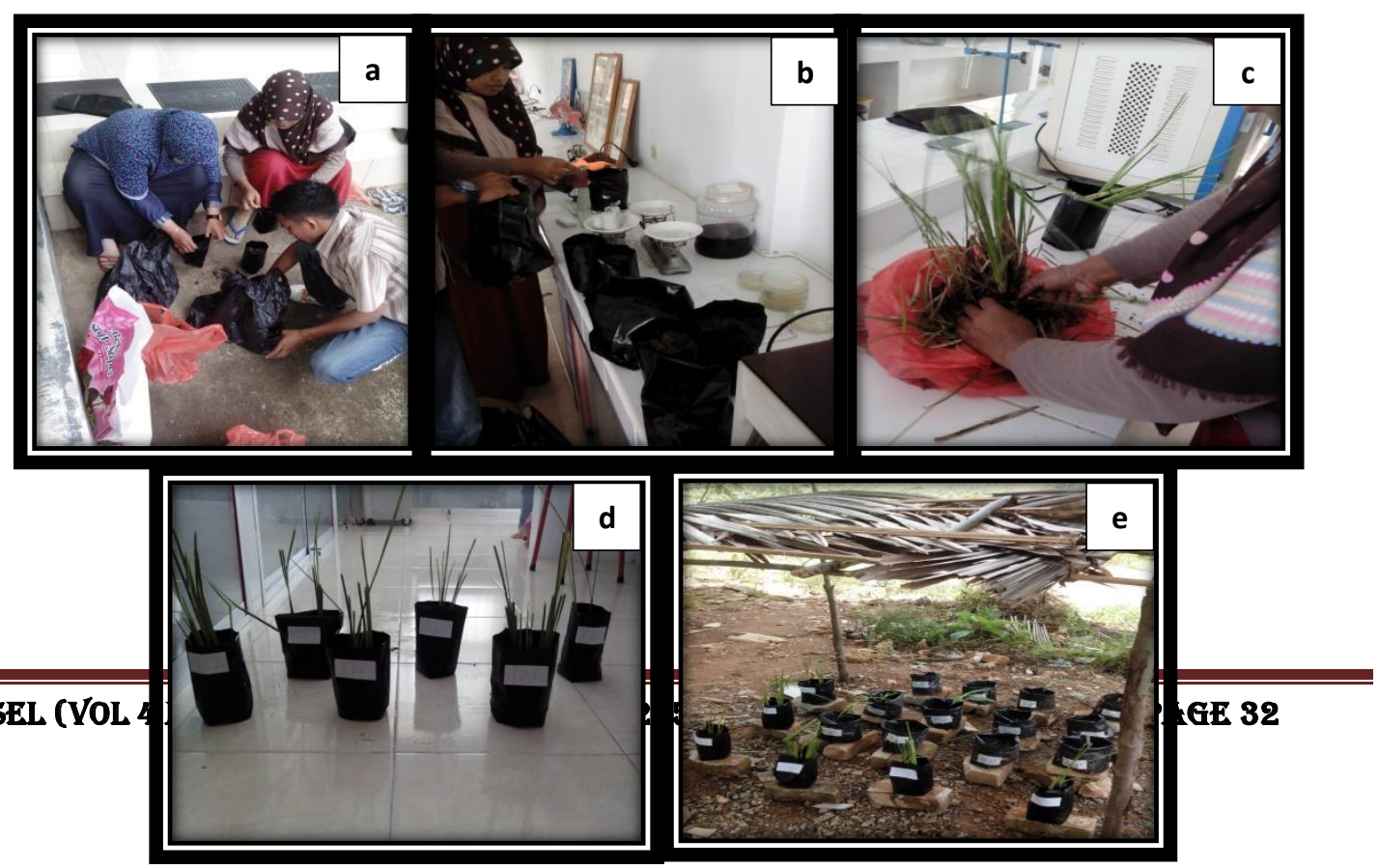




\section{Gambar 1. Proses Penanaman Akar Wangi}

a. Persiapan Tanah ke Polibeg, b. Tanah ditimbang, c. Proses pemisahan Akar Wangi, d. Tanaman akar wangi sudah siap untuk di bawa ke lapangan, $c$. tanaman akar wangi siap untuk diamati

\section{Pengujian logam Berat Timbal (Pb) Setelah Penanaman Akar Wangi}

Berdasarkan hasil Pengujian logam berat timbal $(\mathrm{Pb})$ pada tanah setelah penanaman dapat dilihat pada tabel 3 .

Tabel 3. Persentase Akumulasi Timbal

\begin{tabular}{|c|c|c|c|}
\hline Perlakuan & $\begin{array}{c}\text { Konsentrasi Timbal } \\
\text { pada Tanah Awal }\end{array}$ & $\begin{array}{c}\text { Konsentrasi Timbal } \\
\text { Pada Tanah Akhir }\end{array}$ & $\begin{array}{c}\text { Persentase } \\
\text { Akumulasi Timbal } \\
(\boldsymbol{\%})\end{array}$ \\
\hline A1 & 0,2881 & 0,0822 & 71,46 \\
\hline A2 & 0,2892 & 0,0811 & 71,95 \\
\hline A3 & 0,2875 & 0,0810 & 71,82 \\
\hline B1 & 0,1605 & 0,0452 & 71,83 \\
\hline B2 & 0,1712 & 0,0495 & 71,08 \\
\hline B3 & 0,1522 & 0,0400 & 73,71 \\
\hline C1 & 0,1106 & 0,0323 & 70,79 \\
\hline C2 & 0,1115 & 0,0332 & 70,22 \\
\hline C3 & 0,1122 & 0,0311 & 72,24 \\
\hline
\end{tabular}

Dari tabel 3 dapat dijelaskan bahwa persentase penurunan akumulasi timbal berkisar antara $71,08 \%-73,71 \%$. Sedangkan rata-rata penurunan logam berat timbal $(\mathrm{Pb})$ dapat dilihat pada tabel 4 .

Tabel 4. Rata - rata Konsentrasi Logam Berat Timbal $(\mathrm{Pb})$ pada Tanah sebelum dan sesudah penanaman Akar Wangi

\begin{tabular}{|c|c|c|}
\hline Lokasi & $\begin{array}{c}\text { Konsentrasi Timbal pada Tanah } \\
\text { Awal } \pm \text { SD }\end{array}$ & $\begin{array}{c}\text { Konsentrasi Timbal Pada Tanah } \\
\text { Akhir } \pm \text { SD }\end{array}$ \\
\hline A & $0,288 \pm 0.000^{\mathrm{a}}$ & $0,0814 \pm 0.006^{\mathrm{a}}$ \\
\hline B & $0,161 \pm 0.009^{\mathrm{b}}$ & $0,0449 \pm 0.0005^{\mathrm{b}}$ \\
\hline C & $0,111 \pm 0.008^{\mathrm{c}}$ & $0,0322 \pm 0.001^{\mathrm{c}}$ \\
\hline Rata rata & $0,187 \pm 0.0791^{\mathrm{e}}$ & $0,0528 \pm 0.0223^{\mathrm{f}}$ \\
\hline
\end{tabular}


Keterangan : Superskrip dengan huruf yang sama tidak berbeda nyata $(\alpha=5 \%)$

Berdasarkan hasil Analysis Of Variance (ANOVA) one way menunjukkan bahwa penanaman akar wangi dapat menurunkan konsentrasi tanah tercemar logam berat Timbal $(\mathrm{Pb})\left(\mathrm{F}_{\text {hitung }}>\mathrm{F}_{\text {tabel }}\right)$.

Hasil uji lanjut dengan menggunakan Uji Beda Nyata Terkecil (BNT) menunjukkan bahwa penanaman akar wangi pada tanah tercemar logam berat Timbal $(\mathrm{Pb})$ pada lokasi $\mathrm{A}$ berbeda nyata dengan penanaman akar wangi pada tanah tercemar logam berat Timbal $(\mathrm{Pb})$ pada Lokasi B dan C. Sedangkan penanaman akar wangi pada Tanah tercemar logam berat Timbal $(\mathrm{Pb})$ pada Lokasi $\mathrm{B}$ juga berbeda nyata dengan penanaman akar wangi pada tanah tercemar logam berat $(\mathrm{Pb})$ pada Lokasi $\mathrm{C}$.

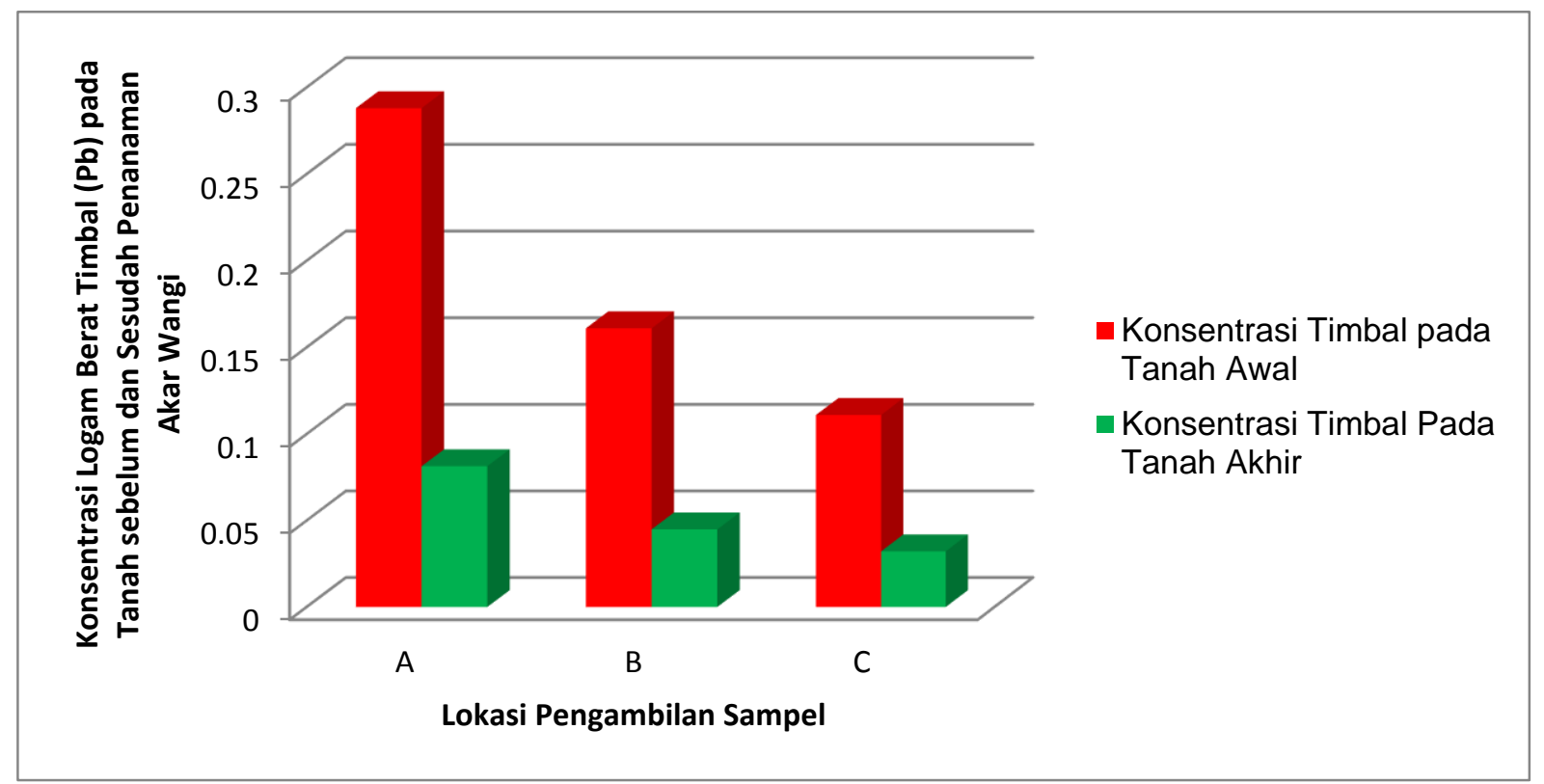

\section{KESIMPULAN DAN SARAN}

\section{Kesimpulan}

Berdasarkan hasil dan pembahasan yang telah dikemukakan, maka dapat disimpulkan sebagai berikut:

1. Terdapat Logam berat Timbal di perkebunan Waiheru Kota Ambon

2. Kandungan logam berat timbal dalam tanah perkebunan Waiheru masih berada di bawah ambang batas aman yaitu 0,1114 - 0,2882 ppm. 
3. Akar Wangi Mampu meremediasi Tanah Tercemar Logam Berat berkisar antara 71,08 \%$73,71 \%$.

\section{Saran}

Dari kesimpulan yang peneliti kemukakan, maka yang menjadi saran dalam penelitian ini adalah perlu dilakukan remediasi tanah di perkebunan sayur Waiheru agar logam berat timbal yang ada tidak semakin hari semakin meningkat. Selain itu, dalam proses pemupukan perlu memperhatikan konsentrasi pupuk, sehingga kedepan tidak memperparah kondisi tanah di lingkungan perkebunan sayur Waiheru.

\section{DAFTAR PUSTAKA}

Akhila, A dan Rani, M. 2002. Chemical Constituents and Essential Oil Biogenesis in Vetiveria zizaniodes. Didalam Massimo Maffei. Vetiveria : The Genus Vetiveria. Taylor and Francs Ind. New York.

Baker AJM, Reeves RD, Hajar ASM. 1994. Heavy metal accumulation and tolerance in British populations of the metallophyte Thlaspi caerulescens J.\&C. Presl (Brassicaceae). New Phytol 127:61-68

Chaudhry, T.M., Hayes, W.J., Khan, A.G. and Khoo, C.S. (1998): Phytoremediation focusing on accumulator plants that remediate metalcontaminated soils, Australian Journal of Ecotoxicology. 4; 37-51.

Chojnacka, K., Chojnacki A., Go'recka H. 2005. Biosorption of $\mathrm{Cr} 3+, \mathrm{Cd} 2+$ and $\mathrm{Cu} 2+$ ions by blue-green algae Spirulina sp.: kinetics, equilibrium and the mechanism of the process, Chemosphere. 59: 75-84.

Darmono. 1995. Logam dalam Sistem Makhluk Hidup. UI-Press, Jakarta.

Ebbs S, Kochian L, Lasat M, Pence N, Jiang T. 2000. An integrated investigation of the phytoremediation of heavy metal and radionuclide contaminated soils: from laboratory to the field. Di dalam: Wise DL, Trantolo DJ, Cichon EJ, Inyang HI, Stottmeister U (ed). Bioremediation of Cotaminated Soils. New York: Marcek Dekker Inc. hlm 745-769. 
Feller AK. 2000. Phytoremediation of soils and waters contaminated with arsenicals from former chemical warfare installations. Di dalam: Wise DL, Trantolo DJ, Cichon EJ, Inyang HI, Stottmeister U (ed). Bioremediation of Cotaminated Soils. New York: Marcek Dekker Inc. hlm 771-786.

Greenfield, J.C. (1989), Vetiver grass (Vetiveria), the ideal plant for vegetative soil and moisture conservation, The World Bank, Wahington D.C.

Mariti, Q. 2005. Pemeriksaan Cemaran Pb(II) Pada Daun Teh (Camellia sinensis L.O. Kuntze) yang Ditanam di Pinggiran Jalan di Daerah Alahan Panjang Sumatra Barat Secra Spektrofotometri Serapan Atom. Skripsi S-1. Padang. Fakultas Matematika dan Ilmu Pengetahuan Alam. Universitas Andalas. 